\title{
Effect of Fixed Array AAC Graphic Symbols on Sentence Construction
}

\author{
Sangeun Shin \\ Department of Communication Disorders, Ewha Womans University, Seoul, Korea
}

Correspondence: Sangeun Shin, PhD

Department of Communication Disorders,

Ewha Womans University, 52 Ewhayeodae-gil,

Seodamun-gu, Seoul 03760, Korea

Tel: $+82-2-3277-2120$

Fax: +82-2-3277-2122

E-mail: newvil78@gmail.com

Received: April 5, 2017

Revised: May 19, 2017

Accepted: May 22, 2017

This study was supported by the research fund of Gyeonggi-do Assistive Technology Research \& Assistance Center.

\begin{abstract}
Objectives: Despite the dominant use of grid-based augmentative and alternative communication (AAC) displays, the effect of fixed array of graphic symbols has not been thoroughly studied, which makes it challenging for clinicians to provide evidence-based AAC intervention to individuals with complex communication needs. The current study aimed to determine the effect of fixed array symbols on sentence composition. Methods: Thirtytwo healthy adults between 20 to 30 years old participated in the study. They were asked to locate three symbols in a fixed array condition and a non-fixed array condition for 25 identical noun-adverb-verb target sentences. The difference in accuracy and response time was analyzed by using a non-parametric two-related samples test and a Spearman correlation test. Results: Although there was no difference in the number of correct responses, participants showed significantly faster responses in the fixed array condition than in the non-fixed condition. Regardless of the selection order, participants located symbols faster in the fixed array condition. As the number of exposures to the located symbols increased, the total selection time in the fixed array condition decreased moderately. Conclusion: The findings support the idea that a fixed array condition may facilitate locating a sequence of graphic symbols in an AAC system by reducing cognitive load in recalling the location of target symbols.
\end{abstract}

Keywords: Fixed array, Grid layout, Sentence construction task, Augmentative and alternative communication (AAC), Graphic symbols
그림상징 기반의 보완대체의사소통(augmentative and alternative communication, AAC)을 이용하여 사용자가 효과적으로 의 사소통하도록 도모하기 위해서는 그림상징과 관련된 다양한 요인 들을 이해할 필요가 있다(Beukelman \& Mirenda, 2012; Light \& Drager, 2002, 2007). 여기에는 상징의 선호도, 도상성, 문화적 영향 등과 같은 상징자체의 특징도 포함하지만(Barton, Sevcik, \& Romski, 2006; Huer, 2000; Choi, Kim, Yeon, Kim, \& Hong, 2016; Dada, Huguet, \& Bornman, 2013; Emms \& Gardner, 2010; Harmon et al., 2014; Huang \& Chen, 2011; Lee \& Park, 2016; Park et al., 2016; Stephenson, 2009; Tsai, 2013; Visser, Alant, \& Harty, 2008; Yeon, Kim, \& Park, 2016) 사용자가 원하는 그림상징을 AAC 시스템에서 정확하고 빠르게 찾는 데에 영향을 끼치는 상징들이 배치되는 디 스플레이에 대한 고려도 중요하다(Higginbotham, Shane, Russell,
\& Caves, 2007; Light \& Drager, 2002; Mizuko, Reichle, Ratcliff, \& Esser, 1994; Olin, Reichle, Johnson, \& Monn, 2010; Wagner, Shaffer, \& Swim, 2012; Wilkinson \& Hennig, 2007).

디스플레이는 화면이 변하지 않는 고정 디스플레이(fixed display) 와 화면의 전환이 가능한 역동적 디스플레이(dynamic display)로 크게 구분된다. 고정 디스플레이는 화면의 크기에 따라 포함할 수 있는 상징의 수와 크기에 제한을 받으며 많은 어휘를 포함할 수 없 다는 단점이 있다. 그러나 임상에서는 대부분의 무발화 아동들의 $\mathrm{AAC}$ 중재를 시작할 때 의사소통판(communication board)과 같은 비전자적 로우테크(low-tech)가 사용되는 경우가 많고(Light \& Drager, 2007), 초기 중재시 많은 어휘를 필요로 하지 않는 초기의 사소통자 또는 중증의 복합장애인에게는 개별 상징에 미리 음성을 녹음하거나 저장하여 산출시키는 전자적 장치인 미드테크(mid- 
tech)가 사용되기도 하기 때문에(Arroyo, Goldfarb, Cahill, \& Schoepflin, 2010) 이들 장치에 적용되는 고정디스플레이의 사용 가치는 높다고 볼수 있다.

반면에 역동적 디스플레이는 화면에 제시되는 그림상징을 선택 하면 관련된 상징들로 이루어진 다른 페이지로 전환되기 때문에 다 양한 페이지에 걸쳐서 그림상징을 위치시킬 수 있다는 장점이 있다. 따라서 한 화면에 제시하는 상징의 수를 줄이면서도 어휘수에 제 한 없이 하이테크(high-tech) AAC에 프로그램화하여 사용할 수 있다(Reichle, Dettling, Drager, \& Leiter, 2000; Wagner \& Jackson, 2006; Wilkinson \& Hennig, 2007). 그러나 역동적 디스플레이를 효과적으로 사용하기 위해서는 화면에 보여지는 페이지에 원하는 그림상징이 보이지 않는다 하더라도 시스템 안에 그림상징이 포함 되어 있다는 것을 인지할 수 있어야 하며 목표상징이 위치한 페이 지의 위치를 기억하여 다단계에 걸쳐 정확하게 연결된 상징들을 선 택할 수 있는 능력을 요한다. 이러한 상징의 탐색(navigation)과 선 택(selection) 과정에서는 인지적 부담이 가중될 수 있다(Drager et al., 2004; Drager, Light, Speltz, Fallon, \& Jeffries, 2003; Lee, Lee, Kim, \& Yeon, 2015; Wagner et al., 2012, Wagner \& Shaffer, 2015). 특히 아동들의 경우 역동적 디스플레이의 여러 페이지 중 하나에 숨어 있을 그림상징을 탐색하여 찾아내기란 이들에게 쉬운 일이 아닐 수 있으며(Drager et al., 2003), 뇌손상을 입어 인지적 부담이 수행에 민감하게 작용할 수 있는 성인 사용자에게도 역동적 디스 플레이의 사용은 다소 어려울 수 있다(Wallace \& Hux, 2014).

두 디스플레이 유형 외에 사진이나 그림 이미지를 기반으로 하여 미리 녹음된 목표 발화를 산출하도록 하는 시각적장면 디스플레 이(visual scene display, VSD)도 있으나(Beukelman, Hux, Dietz, McKelvey, \& Weissling, 2015; Olin et al., 2010; Wilkinson \& Light, 2014 ) 실제 사용자를 대상으로 임상효과가 충분히 입증되지 않았 고 현장에서의 활용도도 낮은 편이기 때문에(Thistle \& Wilkinson, 2015) 본 연구에서는 다루지 않기로 한다.

기술한 바와 같이 비록 고정디스플레이와 역동적 디스플레이가 가지고 있는 특징이 서로 다르지만 두 유형 모두 열과 행으로 이루 어진 격자 레이아웃(grid layout)에 그림상징들을 배열한다는 공통 점이 있다. 그림상징들이 단일 화면에 배치되었느냐 아니면 여러 화 면 중 하나에 배치되어 서로 연결되어 있느냐의 차이점만 있을 뿐 화면에 제시되는 상징의 위치가 매번 바뀌는 것은 아니므로 수정 을 하여 바꾸지 않는 이상 한 화면 내에서 고정된 배열(fixed array) 에 놓이게 된다.

그림상징을 고정된 위치에 놓고 사용할 경우 상징에 접근하는 움 직임이 반복되면서 학습이 이루어지기 때문에 운동 계획의 자동화 (motor planning automaticity)를 발생하여 보다 효율적으로 목표 상징에 접근할 수 있다는 주장이 있다(Thistle \& Wilkinson, 2015). 이것은 마치 키보드 자판에 각 철자들의 위치가 고정되어 있어서 글을 입력할 때에 자판의 철자를 하나하나 눈으로 확인하여 찾을 필요 없이 운동계획의 자동화에 의해서 인지적 부담 없이 타이핑 을 하는 원리와 같다(Grabowski, 2010). 이러한 이유로 임상에서는 실제로 언어치료사들이 디스플레이에 새로운 상징을 추가할 때에 기존의 상징이 놓였던 자리를 가급적 바꾸지 않는 편이라고 한다 (Thistle \& Wilkinson, 2015).

그러나 실제로 상징이 고정된 배열에서 운동 계획의 자동화가 이 루어져 수행변화로 나타날 수 있는지에 대해서는 아직까지 보고된 바가 없어서 임상가들의 경험과 주장을 뒷받침할 만한 경험적 근거 가 부족한 실정이다. 따라서 본 연구에서는 증가하는 성인 AAC 사 용자의 수요와 요구에 대비하여(Seong, Lim, Kim, \& Park, 2013) 효 과적인 $\mathrm{AAC}$ 중재의 기틀을 마련하고자 정상성인을 대상으로 고정 배열이 주는 효과에 대한 기초자료를 마련하고자 하였다. 특히 성 인 사용자의 사회적 참여를 증진시키기 위하여(Beukelman \& Mirenda, 2012) 단단어 발화가 아닌 문장 발화에 초점을 맞추어 다중 의 그림상징 결합을 통한 문장구성과제를 실시하였다. 전체 문장을 구성하는 데에 소요된 시간과 정확도를 분석하고 각각의 상징을 선 택할 때마다 고정된 배열이 일관되게 영향을 주는지를 살펴봄으로 써 운동계획의 자동화가 단기간에 그림상징의 선택 순서에 상관없 이 이루어지는지를 살펴보았다. 세부 연구질문은 다음과 같다.

첫째, 그림상징들을 선택하여 문장을 구성할 때 정반응수와 반 응시간에 있어서 고정배열과 비고정배열 간에 차이가 있는가?

둘째, 그림상징의 선택 순서에 따라 고정배열과 비고정배열 간에 반응시간의 차이가 있는가?

셋째, 배열 조건에 따라 노출횟수와 전체 상징선택에 소요된 반 응시간 간의 상관관계는 어떠한가?

\section{연구방법}

\section{연구대상}

본 연구는 서울 및 경기도에 거주하는 만 20세부터 39세의 정상 성인 33명을 대상으로 하였다. 피험자들은 모두 (1) 한국어가 모국 어이며, (2) 고졸 이상의 학력을 가졌으며, (3) Snellen 시력측정표 (reduced Snellen chart)의 비영어권 모드에서 양쪽 눈 모두 20/100 또는 그 이상의 시력척도를 통과하고(Ross \& Wertz, 2003), (4) 수 용 및 표현어휘력검사(REVT; Kim, Hong, Kim, Jang, \& Lee, 2009) 결과 수용어휘력점수가 모두 정상 범주(-1 SD 이상)에 속하며, (4) 
Korean version of the Western Aphasia Battery (K-WAB; Kim \& $\mathrm{Na}, 2001)$ 의 '읽기' 하위 검사 중 '글명령'의 5 문항에 대하여 모두 정 반응을 보이고, (5) 정신 및 신경학적 질환 병력 또는 언어 및 말 장 애 결함의 이력이 없는 사람으로 선정하였다.

총 33 명의 피험자가 참여하였으나 이 중 한 명은 친숙화 과제에 서 모든 항목에 대하여 정반응을 보였으나 본 실험에서는 목표어 '다시'를 잘못된 그림상징으로 일관적으로 선택하는 오류를 보여 자료분석에서는 제외하였다. 최종적으로 자료분석에 포함된 22명 의 피험자들의 평균연령은 26.75 년이고(SD = 7.05), 평균교육년수 는 15.69년(SD = 1.82)이며, REVT-수용어휘점수의 평균은 174.88 점( $\mathrm{SD}=3.27)$ 이었다. 피험자 모집 환경이 서울소재의 여대에서 주 로 이루어진 이유로 여성으로만 구성되었다. 선별검사와 본 실험은 각 피험자로부터 연구동의서에 서명을 확보한 후에 실시되었다.

\section{실험과제 및 절차}

어휘 선정

피험자의 어휘습득 및 단어의 출현빈도가 과제수행에 미치는 영 향을 최소화하기 위하여 '초등학생 교육용 기초 어휘 선정 연구' (Chang, Jeon, Shin, \& Kim, 2014)에서 보고된 단어 중 명사, 부사, 동 사 범주에서 각각 5 개씩의 어휘를 발췌하였다. 명사는 모두 2 음절의 구체명사(예: 그릇, 의자, 사과, 양말, 비누)로 하였으며 다양한 의미 의 단어를 제시하기 위하여 총 5 가지의 서로 다른 의미적 카테고리 (예: 식기, 가구, 음식, 의류, 욕실용품)에서 선택되었다. 부사는 상태 나 정도를 나타내는 2 음절의 성상부사로 구성하였다(예: 계속, 빨리,
지금, 많이, 다시). 동사는 동작동사만을 사용하였고 대화상황에서 는 용언의 기본형(예: 찾다)이 아닌 해요체의 어미형태(예: 찾아요) 가 보다 자연스럽게 사용된다는 점을 감안하여 다섯 개의 어휘를 포함하였다(예: 찾아요, 잡아요, 던져요, 놓아요, 버려요). 각 단어는 품사 내에서 글자수를 통일하였으며 품사간에 의미관계가 높은 단 어는 외생변인으로 작용할 가능성이 있으므로 포함시키지 않았다.

모든 자극어는 3 어 조합의 글로 제시되었으며 어순은 공통적으 로 명사-부사-동사의 순을 따랐다. 총 25 개의 중복되지 않은 실험 문장이 비고정배열 조건과 고정배열 조건에서 모두 사용되었고 각 각의 단어는 5 회 서로 다른 문장에 반복 사용되도록 배치하였다 (Appendix 1).

\section{그림상징 자극}

실험에 사용된 그림상징은 이화-AAC 상징을 사용하였다. 이 상 징체계는 한국 문화를 고려한 다양한 연령의 $\mathrm{AAC}$ 사용자들이 활 용할 수 있도록 총 23 개의 의사소통 범주에 해당하는 약 1 만 개의 그림상징으로 구성되어 있으며 전문가 집단에 의해 타당성을 입증 받은 바 있다(Park et al., 2016; Yeon et al., 2016). 실험 자극어로 선 정된 15 개의 어휘에 대하여 하나 이상의 그림상징이 있는 경우에는 $\mathrm{AAC}$ 상징연구 경험이 있는 전문가 5 인이 만장일치로 선택한 도상 성이 높은 그림상징을 선택하여 실험자극에 포함하였다. 동사의 경 우 몇몇 그림상징은 동작 그림간의 서로 다른 속성이 영향을 주는 것을 배제하기 위하여 그림에 나타나는 신체부위는 하나의 손동작 만을 포함하도록 하였으며 일부 그림상징에서 소매의 색상, 손의

(1)

Figure 1. Graphic symbols in the fixed array condition. 
크기 등이 전체 상징과 일관되지 않은 경우 Photoshop 7.0 프로그 램을 사용하여 편집하였다.

하나의 그림상징은 가로 $\times$ 세로가 $220 \times 160$ 픽셀로 제작되었다. 그림상징 15 개로 구성된 그림상징판은 가로 $(5$ 개 $\times$ 세로(3개)의 배 열로 전체 $1,100 \times 480$ 픽셀의 크기로 $300 \mathrm{dpi}$ 에 맞추어 제작되었 다. 고정배열 조건에 사용되는 그림상징판은 하나이며 오로지 고정 된 위치가 주는 효과만을 살펴보기 위하여 의도적으로 구문규칙 에 맞추어 상징을 배열하지 않았다(Figure 1). 비고정배열 조건에 사용되는 그림상징판은 같은 규격으로 동일한 상징에 의해 채워졌 으나 고정배열 조건과 다르게 각각의 목표문장에 대하여 제시되는 15 개상징의 위치가 모두 다르도록 제작되었다.

피험자가 문장구성을 위해 세 개의 그림상징을 선택할 때에 첫 번째 선택과 두 번째 선택, 그리고 세 번째 선택 간의 이동거리가 반 응시간에 영향을 줄 수 있으므로 비고정배열과 고정배열 조건 모 두 동일한 일련의 상징위치가 25 개의 항목에 대하여 사용되도록 하였다. 단, 두 조건에서 동일한 목표문장이 사용되는 만큼 해당상 징들의 위치가 학습되어 후행 과제에 영향을 줄 수 있으므로, 이를 배제하기 위하여 각 목표문장에 대하여 동일한 상징위치들이 두 조건 간에 사용되지 않도록 하였다.

\section{실험절차}

실험은 조용하고 독립된 공간에서 연구자와 피험자만 입실한 상 태에서 진행되었다. 피험자로부터 실험참여에 대한 서면 동의서를 받은 뒤, 면담 및 선별검사를 실시하였고 피험자 모집 조건에 부합 하는 사람만을 본 실험에 포함하였다. 실험에 사용되는 그림상징에 대한 친숙도가 과제수행에 영향을 줄 수 있기 때문에 그림상징 15 개와 연습문항에 사용되는 상징들에 대하여 친숙해지는 단계를 밟았으며, 피험자가 그림상징을 정확하게 기억하고 있는지를 살펴 보기 위하여 모든 상징에 대하여 대면이름대기과제를 실시하였다. 오반응을 보인 경우 피드백을 주어 올바른 상징의 이름을 알려주 고 다시 한번 이름대기과제를 실시하여 첫 시도 때 $100 \%$ 의 정반응 이 나오는지를 확인한 뒤 본 실험을 실시하였다.

본 실험에 사용된 그림상징을 이용한 문장구성과제는 E-Prime 2.0 (Schneider, Eschman, \& Zuccolotto, 2002)을 통해 제작되었다. 피험자는 화면으로 제시되는 과제지시문을 읽고 연습문항을 수행 한 후 고정배열 조건 또는 비고정배열 조건 중의 하나를 실시하였 다. 두 배열 조건의 제시되는 순서가 미치는 영향을 배제하기 위하 여 과제 제시순서는 피험자집단에 대하여 균형배정(counter balanced)하였다.

과제절차는 Fixation 화면이 $500 \mathrm{~ms}$ 동안 나타난 후 $100 \mathrm{~ms}$ 간격
의 blank 화면이 나타났다가 사라지면 목표문장이 화면 중앙에 글 로 제시되도록 하였다. 피험자마다 문장을 읽고 이해하는 처리시 간이 다르므로 글을 충분히 읽고 기억할 수 있도록 글의 제시 시간 은 통제하지 않고 본인이 조절하도록 하였다. 피험자가 글을 다 읽 었으면 화면 중앙의 글 밑에 위치한 마우스 커서그림 위치에 마우 스를 위치시켜 클릭하면 $100 \mathrm{~ms}$ 간격의 blank 화면이 나타난 후 바 로 그림상징판이 화면에 나타나도록 하였다. 이는 첫번째 상징을 선 택하는 시작 위치를 모든 항목에 대하여 통일시키기 위함이다. 피 험자는 15 개의 그림상징으로 구성된 상징판에서 앞서 읽었던 글에 해당하는 그림상징 세 개를 최대한 정확하고 빠르게 선택하게 된 다. 피험자의 반응시간(ms)과 정반응은 E-Prime 2.0과 Microsoft Excel 프로그램을 사용하여 자동 산출되도록 하되, 그림상징판이 화면에 제시되는 순간부터 마지막 세 번째 그림상징을 선택한 순간 까지의 시간을 총 반응시간으로 하였다. 아울러 첫 번째와 두 번째 의 그림상징을 선택하는 시간을 각각 측정함으로써 문장 구성에 필요한 각각의 어휘 선택에 있어서 배열 조건의 유형이 영향을 끼치 는지를 살펴보았다.

\section{자료분석 및 통계처리}

비고정배열과 고정배열의 조건에서의 정반응수와 반응시간의 차이는 데이터가 비정규분포의 특성을 갖는 점을 감안하여 비모 수통계방법인 윌콕슨 부호-순위 검정(Wilcoxon signed-rank test) 을 통하여 살펴보았다. 또한 각각의 상징배열 조건에서 25 개 항목 에 대하여 과제를 수행하면서 상징의 위치에 노출되는 회수에 따 라 반응시간에 차이가 있는지를 살펴보기 위해 스피어만 순위상관 계수(Spearman rank correlation coefficients)를 산출하였다. 자료 분석은 IBM SPSS Statistics version 24 프로그램을 사용하여 실시 되었고 유의수준 .05 에서 검증하였다.

\section{연구결과}

\section{배열 조건 간의 정반응수와 반응시간 비교}

평균정반응수는 비고정배열에서 $24.41(\mathrm{SD}=.95)$, 고정배열에서 $24.41(\mathrm{SD}=.91)$ 로 서로 동일하였으며 Wilcoxon signed-ranks test 를 실시한 결과 통계적으로도 차이가 없었다 $(Z=.000, p=1.000)$.

반응시간 분석은 고정배열과 비고정배열 조건에서 그림상징을 정확하게 선택하여 목표문장을 구성한 항목에 대해서만 실시되었 다. 각 조건에서 오반응이 나타난 19 개의 항목을 제외한 총 781 개의 정반응 항목에 대하여 평균전체반응시간(total response time)과 표준편차를 살펴본 결과가 Table 1에 제시되어 있다. 고정배열에서 
Table 1. Response time (ms) in the sentence composition task for the fixed and non-fixed array conditions

\begin{tabular}{lcc}
\hline & Non-fixed array $(\mathrm{N}=781)$ & Fixed array $(\mathrm{N}=781)$ \\
\hline 1st symbol selection & $1,359.14(511.12)$ & $1,232.77(455.32)$ \\
2nd symbol selection & $1,560.58(1,063.21)$ & $1,347.28(824.24)$ \\
3rd symbol selection & $1,456.23(811.39)$ & $1,245.71(669.58)$ \\
Total & $4,375.94(1,642.74)$ & $3,825.76(1,416.41)$ \\
\hline
\end{tabular}

Values are presented as mean (SD).

의 평균전체반응시간은 $3,825.76 \mathrm{~ms}(\mathrm{SD}=1,416.41)$ 로 비고정배열 의 평균인 4,375.94 ms ( $\mathrm{SD}=1,642.74)$ 보다 약 $550.18 \mathrm{~ms}$ 짧았으며 이러한 차이는 Wilcoxon signed-ranks test를 실시한 결과 통계적 으로 유의하였다 $(Z=-8.383, p<.001)$ (Figure 2$)$.

\section{그림상징 선택 순서에 대한 배열 조건 간의 반응시간 비교}

피험자가 목표문장을 구성하기 위하여 두 배열 조건 간에 보였 던 전체반응시간의 차이가 그림상징을 선택하는 순서와 무관하게 동일하게 나타나는지를 살펴보았다. 각 조건에서의 평균반응시간 과 표준편차는 Table 1에 제시된 바와 같다. 첫 번째 그림상징을 선 택하기까지 소요된 평균반응시간은 고정배열이 비고정배열보다 약 $126.37 \mathrm{~ms}$ 짧았으며, 두 번째 선택에 대한 평균반응시간은 고정 배열이 비고정배열보다 약 $213.3 \mathrm{~ms}$ 짧았고, 마지막 그림상징 선택 에 소요된 평균반응시간은 고정배열이 비고정배열보다 약 210.52 $\mathrm{ms}$ 짧은 것으로 나타났다. 각 선택 순서별 반응시간의 차이는 Wilcoxon signed-ranks test를 실시한 결과 첫 번째 선택에서 $Z=-5.763$, $p<.001$, 두 번째 선택에서 $Z=-4.963, p<.001$, 세 번째 선택에서는 $Z=-6.135, p<.001$ 로 모두 통계적으로 유의하였다(Figure 2).

\section{노출횟수와 반응시간 간의 상관관계}

그림상징의 배열 조건별로 노출횟수와 전체반응속도 간의 상관 관계를 Spearman rank correlation 분석을 통해 살펴본 결과가 Figure 2에 제시되어 있다. 비고정배열에서는 $r=-.085$ ( $p=.018)$ 로 매 우 약한 정도의 부적 상관관계가 나타났으며 고정배열에서는 $r=$ -.338 ( $p<.001)$ 로 중간 정도의 부적 상관관계가 나타났다(Cohen, $1988,1992)$. 즉, 두 조건에서 모두 과제의 문항수가 증가할수록 반응 시간이 유의하게 짧아졌으며 이러한 관계는 고정배열이 비고정배 열보다 더 강한 것으로 나타나 보다 높은 상관이 있음을 보여주었다.

\section{논의 및 결론}

본 연구는 성인 AAC 사용자를 위한 효과적인 AAC 중재방안을

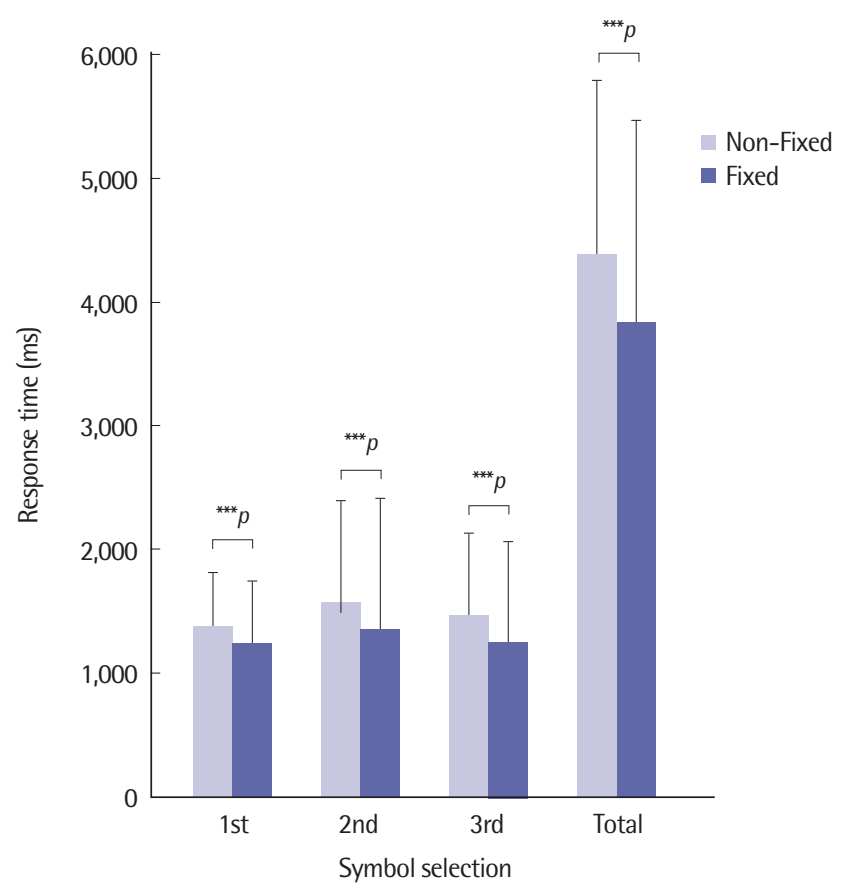

Figure 2. Response time on the first, second, third, and total symbol selections during sentence construction task for the fixed array and non-fixed array conditions.

${ }^{* * *} p<.001$.

모색하고 임상에서 활용할 수 있는 경험적 근거자료를 마련하고자 그림상징의 복수선택을 통한 문장구성에 있어서 상징의 배열 조건 이 수행에 영향을 주는지를 살펴보았다. 첫 번째 연구질문은 그림 상징의 고정배열과 비고정배열 간에 3어 조합의 문장구성을 수행 함에 있어서 반응시간의 차이가 있는지를 살펴보는 것이었다. 연구 결과 정상 성인들은 고정배열 조건에서 더 빠른 문장구성을 보이 는 것으로 나타나 AAC 그림상징들의 결합을 통하여 문장을 산출 할 때에 고정된 상징배열이 주는 효과가 있다는 것이 밝혀졌다. 이 러한 긍정적인 효과는 각 상징의 위치가 변하지 않고 고정되어 있기 때문에 격자기반 디스플레이를 사용할 때에 사용자들에게 요구되 는 그림상징의 회상(recall), 재인(recognize), 그리고 상징이 놓여진 위치를 회상해내는 능력(Beukelman \& Mirenda, 1998; Wagner \& Jackson, 2006)에 대한 인지적 부담이 경감되었기 때문으로 보인다. 고정배열에서의 효율적인 그림상징 선택이 밝혀짐으로써 임상 에서 활발하게 사용되고 있는 격자-기반의 디스플레이의 사용에 대한 경험적 근거가 마련되었다는 점에서 본 연구는 임상적 의의를 제공한다. 고정된 위치에 그림상징을 배치할 경우 운동계획의 자동 화로 인하여 상징접근이 용이해진다는 임상가들의 주장(Thistle \& Wilkinson, 2015)을 단축된 반응시간을 통해 우회적으로 뒷받침 해줌으로써 운동계획의 자동화와 상징의 고정배열 간의 관계를 밝 
히는 추후 연구에도 근거를 제공할 수 있을 것으로 기대된다. 또한 그림상징의 잦은 위치 변경이 반응속도에 영향을 준다는 결과는 $\mathrm{AAC}$ 사용자들의 시스템에 상징을 추가할 때에 기존의 자주 사용 하던 상징의 자리를 가급적 피하는 언어치료사들의 관행을 뒷받침 해줌과 동시에 초기에 적절한 어휘를 선택하고 그에 해당하는 그림 상징의 위치를 설정할 때부터 신중을 기해야 한다는 지침을 제공 한다. 성인 AAC 사용자들의 성공적인 AAC 수행에 있어서 의사소 통의 속도가 중요한 요인이라는 점을 감안하면(Atanasoff, McNaughton, Wolfe, \& Light, 1998; Light, Stoltz, \& McNaughton, 1996; McNaughton \& Bryen, 2007), 그림상징의 효과적인 배열과 배열의 지속을 통하여 보다 효과적인 의사소통과 이로 인한 사회참여의 증진(Beukelman \& Mirenda, 2012)이 가능해질 것이라 예측된다.

두 번째 연구질문은 그림상징의 선택 순서에 따라 고정배열과 비 고정배열 간에 반응시간의 차이가 발생하는가를 알아보는 것이었 다. 연구 결과 모든 그림상징의 선택에 있어서 순서와 상관없이 고 정배열에서의 반응이 비고정배열보다 더 빠른 것으로 나타나 첫 번 째 연구질문에서 보고된 고정배열에서의 전체 반응시간의 단축이 비단 특정 선택 순서의 편중됨 없이 모든 선택에 걸쳐서 단축된 결 과물이라는 것이 밝혀졌다. 고정배열에서만 가능했던 그림상징의 위치에 대한 학습된 기억이 일관되게 모든 그림상징을 선택하는 피 험자들의 행동에 걸쳐서 작용된 것으로 보여진다. 이러한 결과는 $\mathrm{AAC}$ 사용자가 그림상징을 사용하여 3 어 조합의 문장 산출상황뿐 만 아니라, 단단어, 구 또는 더 확장된 문장 수준으로 대화를 할 때 에도 상징의 고정된 위치로 인하여 의사소통 속도를 향상시킬 수 있다는 것을 추론하게 해준다. 실제로 $\mathrm{AAC}$ 사용자가 다양한 구문 수준으로 그림상징으로 이용하여 메시지를 구성할 때 일관된 효과 가 나타나는지를 살펴보기 위하여 추후 연구가 필요할 것으로 보 인다. 아울러 고정 디스플레이와 역동적 디스플레이상에서 상징의 위치를 고정시킬 때에 가장 효율적인 접근을 도모할 수 있는 어휘 의 선택과 배치, 그리고 어휘의 범주 구성에 대하여 답을 제시할 수 있는 연구가 필요하겠다.

그림상징의 선택 순서와 상관없이 고정배열에서 빠른 반응이 나 타난다는 본 연구의 결과는 격자기반의 다양한 AAC 도구를 사용 하여 중재를 제공하는 임상가들에게 지침을 제공한다. 가령, 원하 는 그림상징을 탐색해내는 데에 인지적 부담을 많이 느끼는 이들에 게는 역동적 디스플레이를 사용하는 것이 어려울 수 있으므로(Drager et al., 2004; Drager et al., 2003; Lee et al., 2015; Wagner \& Shaffer, 2015; Wallace \& Hux, 2014), 이들에게는 높은 빈도로 사용되 는 중요한 핵심어휘들로 구성된 고정된 하나의 그림상징 배열 세트 를 가지고 중재를 시작할 수 있을 것이다. 우선 단단어 산출을 증진
시키는 훈련을 한 뒤에, 설정한 기준 이상의 수행력을 보이게 되면 동일한 상징판을 사용하여 다양한 2어 조합의 구 또는 문장 산출 로 치료목표를 높일 수 있을 것이다. 이러한 접근은 비단 인지적 결 함이 있는 성인뿐만 아니라 지적 결함이 있고, 언어발달 과정 중인 아동에게도 적용할 수 있는 방법이다. 그 이유는 지적 결함을 동반 한 아동이라 하더라도 복수의 그림상징 결합을 통하여 문장발화 를 할 수 있기 때문이다(Wilkinson, Romski, \& Sevcik, 1994). 만약 대상자의 수행이 향상되어 다양한 어휘상징을 표현할 수 있는 단계 가 되고 그림상징 탐색을 위한 인지능력이 어느 정도 갖추어져 있 다면 많은 어휘를 담을 수 있는 역동적 디스플레이상에서(Reichle et al., 2000; Wagner \& Jackson, 2006; Wilkinson \& Hennig, 2007) 새로운 어휘를 새 페이지에 체계적으로 배열함으로써 상징에 접근 하는 훈련을 할 수 있을 것이다. 고정된 디스플레이에서 역동적 디 스플레이로 전환되는 시점이지만 상징을 해당 페이지의 고정된 위 치에 배치함으로써 확장한 어휘와 확장된 구문을 표현해내는 데에 인지적 부담을 경감시켜 주는 방향으로 나아가야 할 것이다.

정상 성인의 그림선택 순서에 따른 평균반응시간을 살펴보면 사 물명사에 해당하는 첫 번째 그림을 선택할 때보다 부사인 두 번째 와 동사인 세 번째 그림을 선택할 때에 두 배열 조건 간의 차이가 더 벌어지는 것으로 나타났다. 문장구성과제에서의 반응시간의 차이 가 품사의 영향을 받아 발생한 것인지에 대해서는 추후연구가 필요 할 것으로 보인다. 이를 위해서는 각 품사별로 목표 그림상징을 정확 하게 인지하는 데에 소요되는 시간이 수행에 영향을 줄 수 있으므로 품사별로 인지과제에서 나타나는 반응시간을 비교하고 이를 그림 상징의 도상성과 관련하여 논의하는 과정이 필요할 것으로 보인다.

마지막으로 문장구성과제에서의 반응시간과 노출횟수 간의 관 계를 살펴본 결과 배열 조건과 상관없이 모두 부적인 상관관계를 보여 노출횟수가 증가할수록 그림상징 세 개를 선택하여 문장을 구성할 때에 더 빠른 반응을 보이는 것으로 나타났다. 그러나 배열 조건에 따라 그 상관 정도는 다른 것으로 나타났다. 비고정배열 조 건에서는 두 변수 간의 관계가 매우 약했으며 고정배열에서는 그의 4 배에 달하는 중간 정도의 상관관계를 보였다. 이는 회가 거듭될수 록 그림상징의 고정된 위치가 주는 학습효과가 증가하여 그림상징 의 선택을 위한 움직임의 이동경로가 짧고 빠르게 이루어졌으리라 는 것을 짐작하게 해준다.

비고정배열에서 보인 유의한 부적 상관관계는 비록 미약하기는 하지만 나름대로의 의미를 갖는다. AAC 디스플레이에서 그림상징 의 위치가 변하여 예측할 수 없다 하더라도 그림상징 자체에 대한 친숙도와 과제수행 방법에 대한 점진적인 친숙함이 비록 약하지만 기본적으로 사용자에게 유리한 방향으로 영향을 준다는 것을 말 
해주기 때문이다. 그러나 고정과 비고정배열 간의 상관관계의 차이 는 고정된 위치가 주는 별도의 영향을 잘 보여주기 때문에 AAC 중 재를 위해 그림상징을 배치할 때에 잦은 위치 변경은 반응시간에 영향을 줄 수 있으며, 이는 자동화된 운동을 통한 상징 접근을 저 해하는 요소가 될 수 있다는 주장(Thistle \& Wilkinson, 2015)의 근거 자료로 사용될 수 있을 것이다. 단, 본 연구에서는 피험자가 1 회 방문하여 각 조건에 대하여 25 개 문항에 대해서만 노출을 경험 하기 때문에 더 많은 노출 빈도와 장기적인 기간 동안에 피험자들 의 수행이 어떻게 변할지에 대해서는 답을 내어 놓고 있지 못하다.

본 연구의 제한점을 좀더 추가하자면, 그림상징판을 고정 디스플 레이에 가까운 형태로 제시하였기 때문에(즉, 하나의 화면에만 상 징이 제시됨) 다수의 페이지로 구성된 역동적 디스플레이에서 고 정배열의 효과가 실제로 수행에 어떠한 영향을 주게 될지에 대하여 알 수 없다. 만약 상징의 고정된 위치를 통한 학습효과가 역동적 디 스플레이에서 그림상징을 탐색하는 시간에도 긍정적인 영향을 준 다면 이는 역동적 디스플레이 기반의 하이테크 AAC 도구를 사용 하는 많은 사용자들의 효율적인 의사소통을 위해 중요한 고려사항 이 될 것이다.

또한 연구 목적에서 언급된 바와같이 본 연구는 성인 $\mathrm{AAC}$ 사용 자를 위한 기초 자료를 제공하고자 정상성인을 대상으로 실시된 연구이다. 실험조건에서 이루어진 연구의 결과가 실제 AAC 도구 를 사용하는 성인 사용자에게도 동일하게 나타나는지에 대해서는 보다 다양한 장애군을 대상으로 한 임상연구가 필요할 것으로 보 인다. 마지막으로 본 연구는 실험대상자 모집과정에서 남녀 성비를 따로 설정하기 않았으며 모집이 실시된 지리적 여건상 여성들의 참 여가 집중적으로 이루어졌다. 과제에 사용된 그림상징 또한 성별에 민감하게 연관되는 개념들이 아니기 때문에 크게 문제는 되지 않 을 것으로 보여지나 아직까지 성별이 그림상징을 선택하는 데에 영 향을 끼치지 않는다는 연구 결과는 없으므로 다른 성으로의 일반 화에는 주의를 요한다.

\section{REFERENCES}

Arroyo, C. G., Goldfarb, R., Cahill, D., \& Schoepflin, J. (2010). AAC interventions: case study of in-utero stroke. The Journal of Speech and Language Pathology-Applied Behavior Analysis, 5, 32-47.

Atanasoff, L. M., McNaughton, D., Wolfe, P. S., \& Light, J. (1998). Communication demands of university settings for students using augmentative and alternative communication (AAC). Journal of Postsecondary Education and Disability, 13, 32-47.
Barton, A., Sevcik, R. A., \& Ann Romski, M. (2006). Exploring visual-graphic symbol acquisition by pre-school age children with developmental and language delays. Augmentative and Alternative Communication, 22, 10-20. Beukelman, D. R., \& Mirenda, P. (1998). Augmentative and alternative communication: management of severe communication disorders in children and adults. Baltimore, MD: Paul H. Brookes.

Beukelman, D. R., \& Mirenda, P. (2012). Augmentative and alternative communication: supporting children and adults with complex communication needs (4th ed.). Baltimore, MD: Paul H. Brookes.

Beukelman, D. R., Hux, K., Dietz, A., McKelvey, M., \& Weissling, K. (2015). Using visual scene displays as communication support options for people with chronic, severe aphasia: a summary of AAC research and future research directions. Augmentative and Alternative Communication, 31, 234245.

Huer, M. B. (2000). Examining perceptions of graphic symbols across cultures: preliminary study of the impact of culture/ethnicity. Augmentative and Alternative Communication, 16, 180-185.

Chang, H. J., Jeon, H. S., Shin, M. S., \& Kim, H. J. (2014). Study on selection of basic vocabulary for elementary school students: focused on basic vocabulary in the lower grades. Journal of Speech \& Hearing Disorders, 23, 157170.

Choi, E. J., Kim, Y. T., Yeon, S. J., Kim, J., \& Hong, K. H. (2016). Effects of robot and computer-based intervention on learning action word symbols of AAC for children with autism spectrum disorder. Communication Sciences \& Disorders, 21, 744-759.

Cohen, J. (1988). Statistical power analysis for the behavioral sciences (2nd ed.). Hillsdale, NJ: Lawrence Erlbaum.

Cohen, J. (1992). A power primer. Psychological Bulletin, 112, 155-159.

Dada, S., Huguet, A., \& Bornman, J. (2013). The iconicity of picture communication symbols for children with English additional language and mild intellectual disability. Augmentative and Alternative Communication, 29, 360-373.

Drager, K. D., Light, J. C., Carlson, R., D’Silva, K., Larsson, B., Pitkin, L., \& Stopper, G. (2004). Learning of dynamic display AAC technologies by typically developing 3-year-olds: effect of different layouts and menu approaches. Journal of Speech, Language, and Hearing Research, 47, 1133-1148.

Drager, K. D., Light, J. C., Speltz, J. C., Fallon, K. A., \& Jeffries, L. Z. (2003). The performance of typically developing $2 \frac{1}{2}-$-year-olds on dynamic display AAC technologies with different system layouts and language organizations. Journal of Speech, Language, and Hearing Research, 46, 298-312. 
Emms, L., \& Gardner, H. (2010). Study of two graphic symbol-teaching methods for individuals with physical disabilities and additional learning difficulties. Child Language Teaching and Therapy, 26, 5-22.

Grabowski, J. (2010). Speaking, writing, and memory span in children: output modality affects cognitive performance. International Journal of Psychology, 45, 28-39.

Harmon, A. C., Schlosser, R. W., Gygi, B., Shane, H. C., Kong, Y. Y., Book, L., ... \& Hearn, E. (2014). Effects of environmental sounds on the guessability of animated graphic symbols. Augmentative and Alternative Communication, 30, 298-313.

Higginbotham, D. J., Shane, H., Russell, S., \& Caves, K. (2007). Access to AAC: present, past, and future. Augmentative and Alternative Communication, 23, 243-257.

Huang, C. H., \& Chen, M. C. (2011). Effect of translucency on transparency and symbol learning for children with and without cerebral palsy. Research in Developmental Disabilities, 32, 1829-1836.

Kim, H. H., \& Na, D. L. (2001). Paradise.Korean version-Western Aphasia Battery (K-WAB). Seoul: Paradise Welfare Foundation.

Kim, Y. T., Hong, G. H., Kim, K. H., Jang, H. S., \& Lee, J. Y. (2009). Receptive \& expressive vocabulary test (REVT). Seoul: Seoul Community Rehabilitation Center.

Lee, H. J., \& Park, H. J. (2016). Conceptual understanding and preference of preschool-aged children according to type of graphic symbols. AAC Research \& Practice, 4, 65-82.

Lee, Y. G., Lee, H. J., Kim, Y. T., \& Yeon, S. (2015). The performance of Korean children with intellectual disabilities on dynamic AAC technologies with different language organizations. Communication Sciences \& Disorders, 20, 344-353.

Light, J., \& Drager, K. (2002). Improving the design of augmentative and alternative technologies for young children. Assistive Technology, 14, 17-32.

Light, J., \& Drager, K. (2007). AAC technologies for young children with complex communication needs: state of the science and future research directions. Augmentative and Alternative Communication, 23, 204-216.

Light, J., Stoltz, B., \& McNaughton, D. (1996). Community-based employment: experiences of adults who use AAC. Augmentative and Alternative Communication, 12, 215-229.

McNaughton, D., \& Bryen, D. N. (2007). AAC technologies to enhance participation and access to meaningful societal roles for adolescents and adults with developmental disabilities who require AAC. Augmentative and Alternative Communication, 23, 217-229.
Mizuko, M., Reichle, J., Ratcliff, A., \& Esser, J. (1994). Effects of selection techniques and array sizes on short-term visual memory. Augmentative and Alternative Communication, 10, 237-244.

Olin, A. R., Reichle, J., Johnson, L., \& Monn, E. (2010). Examining dynamic visual scene displays: Implications for arranging and teaching symbol selection. American Journal of Speech-Language Pathology, 19, 284-297.

Park, E. H., Kim, Y. T., Hong, K. H., Yeon, S. J., Kim, K. Y., \& Lim, J. H. (2016). Development of Korean Ewha-AAC symbols: validity of vocabulary and graphic symbols. AAC Research \& Practice, 4, 19-40.

Reichle, J., Dettling, E., Drager, K., \& Leiter, A. (2000). Comparison of correct responses and response latency for fixed and dynamic displays: performance of a learner with severe developmental disabilities. Augmentative and Alternative Communication, 16, 154-163.

Ross, K., \& Wertz, R. (2003). Quality of life with and without aphasia. Aphasiology, 17, 355-364.

Schneider, W., Eschman, A., \& Zuccolotto, A. (2002). E-Prime user's guide. Pittsburgh, PA: Psychology Software Tools Inc.

Seong, S. Y., Lim, J. H., Kim, Y. T., \& Park, E. (2013). The prevalence of potential AAC users in Korea: from the early childhood to the adulthood. AAC Research \& Practice, 1, 1-24.

Stephenson, J. (2009). Iconicity in the development of picture skills: typical development and implications for individuals with severe intellectual disabilities. Augmentative and Alternative Communication, 25, 187-201.

Thistle, J. J., \& Wilkinson, K. M. (2015). Building evidence-based practice in AAC display design for young children: current practices and future directions. Augmentative and Alternative Communication, 31, 124-136.

Tsai, M. J. (2013). Adults' preferences between picture communication symbols (PCSs) and Gus communication symbols (GCSs) used in AAC. Research in Developmental Disabilities, 34, 3536-3544.

Visser, N., Alant, E., \& Harty, M. (2008). Which graphic symbols do 4-yearold children choose to represent each of the four basic emotions? Augmentative and Alternative Communication, 24, 302-312.

Wagner, B. T., \& Jackson, H. M. (2006). Developmental memory capacity resources of typical children retrieving picture communication symbols using direct selection and visual linear scanning with fixed communication displays. Journal of Speech, Language, and Hearing Research, 49, 113-126.

Wagner, B. T., \& Shaffer, L. A. (2015). Identifying, locating, and sequencing picture communication symbols: contributions from developmental visuospatial and temporal memory. Evidence-Based Communication Assessment and Intervention, 9, 21-42. 
Wagner, B. T., Shaffer, L. A., \& Swim, O. A. (2012). Identifying, locating, and sequencing visual-graphic symbols: a perspective on the role of visuospatial and temporal memory. Perspectives on Augmentative and Alternative Communication, 21, 23-29.

Wallace, S. E., \& Hux, K. (2014). Effect of two layouts on high technology AAC navigation and content location by people with aphasia. Disability and Rehabilitation: Assistive Technology, 9, 173-182.

Wilkinson, K. M., \& Hennig, S. (2007). The state of research and practice in augmentative and alternative communication for children with developmental/intellectual disabilities. Developmental Disabilities Research Reviews, $13,58-69$.
Wilkinson, K. M., \& Light, J. (2014). Preliminary study of gaze toward humans in photographs by individuals with autism, Down syndrome, or other intellectual disabilities: implications for design of visual scene displays. Augmentative and Alternative Communication, 30, 130-146.

Wilkinson, K. M., Romski, M. A., \& Sevcik, R. A. (1994). Emergence of visual-graphic symbol combinations by youth with moderate or severe mental retardation. Journal of Speech, Language, and Hearing Research, 37, 883895.

Yeon, S. J., Kim, Y. T., \& Park, E. H. (2016). Transparency and name agreement of Korean Ewha-AAC symbols: nouns, verbs, and adjectives. AAC Research \& Practice, 4, 45-63. 
Appendix 1. 문장구성과제에 사용된 자극어 목록

\begin{tabular}{|c|c|}
\hline No & 자극어 ${ }^{a}$ \\
\hline 1 & 양말 많이 버려요 \\
\hline 2 & 그릇 지금 잡아요 \\
\hline 3 & 비누 계속 놓아요 \\
\hline 4 & 의자 다시 찾아요 \\
\hline 5 & 사과 빨리 던져요 \\
\hline 6 & 양말 지금 놓아요 \\
\hline 7 & 그릇 계속 찾아요 \\
\hline 8 & 비누 다시 던져요 \\
\hline 9 & 의자 빨리 버려요 \\
\hline 10 & 사과 많이 잡아요 \\
\hline 11 & 양말 계속 던져요 \\
\hline 12 & 그릇 다시 버려요 \\
\hline 13 & 비누 빨리 잡아요 \\
\hline 14 & 의자 많이 놓아요 \\
\hline 15 & 사과 지금 찾아요 \\
\hline 16 & 양말 다시 잡아요 \\
\hline 17 & 그릇 빨리 놓아요 \\
\hline 18 & 비누 많이 찾아요 \\
\hline 19 & 의자 지금 던져요 \\
\hline 20 & 사과 계속 버려요 \\
\hline 21 & 양말 빨리 찾아요 \\
\hline 22 & 그릇 많이 던져요 \\
\hline 23 & 비누 지금 버려요 \\
\hline 24 & 의자 계속 잡아요 \\
\hline 25 & 사과 다시 놓아요 \\
\hline
\end{tabular}

에서 발췌함. 


\section{국문초록}

\section{고정배열된 AAC 그림상징이 문장구성에 미치는 효과 \\ 신상은}

이화여자대학교 대학원 언어병리학과

배경 및 목적: 격자 레이아웃 기반의 $\mathrm{AAC}$ 디스플레이가 임상현장에서 높은 활용을 보임에도 불구하고 그림상징의 고정된 배열이 주 는 효과에 대해서는 보고된 바가 거의 않다. 본 연구는 복합적인 의사소통 장애를 가진 사람들에게 근거 기반의 $\mathrm{AAC}$ 중재를 제공하고 자 문장구성 과제를 통하여 상징의 고정배열이 주는 효과를 살펴보았다. 방법: 20 대와 30 대로 구성된 32 명의 정상성인이 연구에 참여 하였고 이들에게 고정배열 조건과 비고정배열 조건에서 주어진 문장에 해당되는 그림상징들을 선택하도록 하였다. 실험에 사용된 25 개의 자극어는 명사-부사-동사로 이루어진 문장으로 구성하였으며 두 조건에 동일하게 사용되었다. 피험자들의 과제수행은 정반응수 와 반응시간을 중심으로 비모수통계방법을 사용하여 분석하였다. 결과: 두 배열 조건 모두에서 높은 정반응이 보였으나 반응시간에 있어서는 유의한 차이를 보였다. 고정배열 조건에서 유의하게 더 빠른 반응을 보였으며 이는 그림상징의 선택 순서와 상관없이 일관되 게 비고정배열 조건보다 더 빠른 것으로 나타났다. 노출되는 횟수가 증가할수록 두 배열 조건에서 피험자들의 반응이 유의하게 빨라졌 으나 상관관계는 비고정보다 고정배열 조건에서 더 큰 것으로 나타났다. 논의 및 결론: 본 연구의 결과는 $\mathrm{AAC}$ 시스템에서 일련의 상징 들을 선택 및 결합하여 문장을 구성할 때에 고정된 상징 배열이 긍정적인 영향을 끼친다는 경험적 자료를 제공한다. 아울러 고정배열이 상징의 위치를 회상해내는 데에 필요한 인지적 부담을 감소시켜 전반적인 의사소통 속도를 증진시킨다는 것을 보여준다.

핵심어: 고정 배열, 격자 레이아웃, 문장구성과제, 보완대체의사소통, 그림상징

본 연구는 경기도 재활공학서비스연구지원센터에서 연구비를 지원받아 수행되었음.

\section{참고문헌}

김영태, 홍경훈, 김경희, 장혜성, 이주연(2009). 수용·표현어휘력검사(REVT). 서울: 서울장애인종합복지관.

김향희, 나덕렬(2001). 파라다이스-한국판-웨스턴실어증검사. 서울: 파라다이스 복지재단.

박은혜, 김영태, 홍기형, 연석정, 김경양, 임장현(2016). 이화-AAC 상징체계 개발 연구: 어휘 및 그래픽상징의 타당화. 보완대체의사소통연구, 4, 19-40. 성시연, 임장현, 김영태, 박은혜(2013). 보완대체의사소통(AAC) 잠재 수요 예측 연구: 아동기 및 후천성 성인기 의사소통 장애를 중심으로. 보완대체

의사소통연구, 1, 1-24.

연석정, 김영태, 박은혜 (2016). 이화-AAC 상징체계의 상징투명도와 명명일치도 특성 비교 연구. 보완대체의사소통연구, 4, 45-63.

이유경, 이현정, 김영태, 연석정(2015). 태블릿 PC 기반 보완대체의사소통의 어휘 선택 경로가 일반아동과 지적장애아동의 AAC 어휘표현 정확도 및

선호도에 미치는 영향. 언어청각장애연구, 20, 344-353.

이효주, 박현주(2016). 그림상징 유형에 따른 학령전기 아동의 개념이해 및 선호도. 보완대체의사소통연구, 4, 65-82.

장현진, 전희숙, 신명선, 김효정(2014). 초등학생 교육용 기초 어휘 선정 연구: 저학년 중심으로. 언어치료연구, 23, 157-170.

최은정, 김영태, 연석정, 김동준, 홍기형(2016). 교육용 로봇과 컴퓨터를 활용한 자폐범주성장애 아동의 AAC 동작어 상징 학습 효과. 언어청각장애연

구, 21, 744-759. 